\title{
Pensar lo contemporáneo a través DE LO LÍRICO: LA OBRA DE Nicanor Parra y Roberto Bolaño
}

THINKING THE CONTEMPORARY BY THE LYRICAL: THE WORK OF NICANOR PARRA AND ROBERT BOLAÑO

\author{
Markus Alexander Lenz
}

Universidade de Potsdam

Potsdam, Alemanha

\section{Resumen}

Dos poetas chilenos con similar concepción de la poesía, al tiempo que muy diferentes: Mientras Nicanor Parra es considerado uno de los poetas latinoamericanos más importantes del siglo XX, la poesía del escritor Roberto Bolaño encuentra poca atención en comparación con su prosa. Sin embargo, ambos autores dan respuestas constructivas a las posibles funciones de la poesía contemporánea bajo una epistemología que está basada en un materialismo, que afecta el lenguaje como capacidad emancipadora de cada individuo humano. Una lectura comparativa de dos volúmenes de su poesía, los bien conocidos Poemas y antipoemas de Parra (1954) y el último poemario, Tres (2000), de Bolańo, no solamente demuestra algunos enlaces estructurales. La pregunta urgente acerca de los beneficios de la literatura para sociedades globalizadas, implicando identidades culturales y lingüísticas de alta complejidad, podría beneficiarse de una conciencia revivida de la poesía como formalización histórica y relativa de la lengua, y como instrumento eficaz para reflejar las restricciones del lenguaje en tiempos de su normalización económica y cultural-industrial.

Palabras clave: Nicanor Parra; Roberto Bolaño; Posmodernismo; Tres; Antipoesía.

\section{Resumo}

Dois poetas chilenos com similar concepçáo da poesia e ao mesmo tempo muito diferentes. Na medida em que Nicanor Parra é considerado um dos poetas mais importantes do século XX, a poesia de Roberto Bolaño é pouco atendida pela crítica, se comparada com sua prosa. Porém, ambos os autores dão respostas construtivas às possíveis funçóes da poesia contemporânea, sob uma epistemologia embasada em um materialismo que afeta a linguagem como capacidade emancipadora de cada indivíduo. Uma leitura comparativa de dois volumes de sua poe-

\section{Abstract}

Two Chilean poets with equal and yet different conceptions of poetry: While Nicanor Parra is considered one of the most important Latin American lyricists of the 20th century, the poetry of novelist Roberto Bolaño only finds little attention in comparison to his highly successful prose. Yet both authors give constructive answers to the possible functions of contemporary poetry under an epistemology based upon materialism that affects language as emancipatory capacity of each human individual. A comparative reading of two volumes of their 
sia, os bem conhecidos Poemas y antipoemas (1954), de Parra, e Tres (2000), de Bolaño, não só demostra alguns enlaces estruturais. A pergunta urgente sobre os benefícios da literatura para sociedades globalizadas, implicando identidades culturais e linguísticas de alta complexidade, poderia se beneficiar de uma consciência revivida da poesia como formalização histórica e relativa à língua, e como instrumento eficaz para expressar as restriçōes da linguagem em tempos de sua normalização econômica e cultural.

Palavras-chave: Nicanor Parra; Roberto Bolaño; Posmodernismo; Tres; Antipoesía. poetry, Parra's well known Poemas y antipoemas (1954) and Bolańo's last 'collection of poems' Tres (2000), does not only demonstrate some structural links. The urgent question concerning the benefits of literature among globalized societies, involving highly complex cultural and linguistic identities, could benefit from a revived awareness towards poetry as historically relative formalization of language, but also as an efficient instrument to reflect the restrictions of language in times of its economic and cultural-industrial standardization.

Keywords: Nicanor Parra; Roberto Bolaño; Tres; Antipoetry.

Si se quiere descubrir a vuelo de pájaro entre todos los "grandes escritores" medialmente omnipresentes en las postrimerías del siglo XX e inicios del XXI una voz latinoamericana, entonces destaca, entre celebridades como David Foster Wallace, Haruki Murakami y Michel Houellebecq, el chileno Roberto Bolaño, quien en su obra logra reflexionar lo "actual" en aras de lo global y asimismo establece una relación decidida con la tradición literaria latinoamericana. Novelas como 2666, Detectives salvajes y Una novelita lumpen o colecciones de cuentos como Putas asesinas y Llamadas telefónicas, cuya actualidad se nutre no sólo de la desbordante riqueza de referencias históricas, políticas e histórico-literarias sino sobre todo de su profundidad antropológica, contraponen la fragmentariedad de una realidad globalizada de corte posmoderno y dominada por la economía posindustrial a la universalidad de los temas existenciales como la muerte, la sexualidad y la búsqueda metafísica de sentido. Lo apasionante de estas obras en prosa no es tanto el uso de una lengua colmada de metáforas, de aventuras léxicas o la densidad compleja de las construcciones oracionales, sino más bien la economía diegética de las tramas entretejidas, que buscan una y otra vez el equilibrio perdido entre la determinación individual en el espacio y en el tiempo y el precipitarse al mar ondulante de la casualidad y el cambio. Que una diégesis con tal vigor tiene fuertes vínculos con los logros literarios de los autores latinoamericanos del Boom, del Realismo mágico o también del Modernismo ha sido destacado en innumerables estudios científicos dedicados a la obra de Bolaño. ${ }^{1} \mathrm{Al}$ lado

${ }^{1}$ Cf. p. e. Las monografías recientes de BOLOGNESE, 2009, SOLOTOREVSKY, 2012, RODRÍGUEZ, 2015, o las antologías de LÓPEZ DE ABIADA, 2012, RÍOS BAEZA, 2010, MANZONI, 2002 y 
de los representantes de las vanguardias y de Franz Kafka es Jorge Luis Borges quien figura como uno de los puntos referenciales y fuente de inspiración más importantes para la escritura del novelista.

Sin embargo, con su obra lírica hay otra fuente, que pone de relieve la actualidad y la riqueza de la literatura chilena para la escritura de un chileno mundialmente reconocido y que pone de relieve la importancia de América Latina para aquello que podríamos denominar "literatura mundial" o mejor aún, hablando con Ottmar Ette, "literaturas del mundo" allende los grandes proyectos épicos. ${ }^{2}$ Pues que con frecuencia sigue siendo la forma llamativa de una novela o el ancho lomo de un libro, antańo aparente garante de una jerarquía historiográfica y mimética del siglo XIX, inaugurada en la historia de la literatura de la burguesía, la que determina la percepción de las obras de los distintos autores latinoamericanos. Aunque Bolaño se dedicara en vida a la deconstrucción del discurso formal, después de su muerte, la recepción fue víctima de esta perspectiva limitada que apenas permite homenajear intensa y oportunamente al narrador Bolaño. Entre tanto, el poeta parece quedar expuesto a la sospecha y los prejuicios de una forma elitista menor, que quizás no puede corresponder a los desafíos de un mundo cuya complejidad ni siquiera las grandes novelas pueden dominar. ${ }^{3}$ Un acercamiento más profundo a Bolaño como lírico desdirá esta justipreciación.

Este enfoque es posible cuando nos centramos en una de las fuentes centrales de su poesía y de su escritura en general: Nicanor Parra fue otro poeta chileno con el que Bolaño mantendrá lazos de admiración y respeto y además, un vínculo de continuidad en la búsqueda del papel de la lengua para la superación de los límites cognitivos, que asimismo conforman el punto de partida para una posible trascendencia de lo humano. ${ }^{4}$ Las poesías de Baudelaire y Mallarmé inauguraron esta búsqueda desesperada (cf. BATAILLE, 1957; BLUMENBERG, 1986: 310 ss.) y ortogaron así a la lírica una nueva dimensión ontológica, que en Chile adquirió un tinte antropológico a través

ESPINOSA, 2003. En cuanto a Bolaños y la importancia para la teoría de la novela cf. VALDIVIA OROZCO, 2013, en cuanto a su dimensión politica y antropológica cf. LOY, 2013.

2 A diferencia de algunos conceptos de 'literatura mundial', que pueden conducir a fuertes restricciones metodológicas (MORETTI, 2000), jerarquizaciones lingüísticas (DAMROSCH, 2003) o historiográficas (CASANOVA, 2008), Ottmar Ette propone un concepto alternativo, multilingüe, multilateral y, por eso, en terminos de política literaria más democrático (Cf. ETTE, 2006; 2009 , donde se discute también la importancia de formas cortas de lo literario para ese concepto de 'Literaturas del Mundo').

3 "Por lo que respecta a mis libros debo decir que he publicado cinco poemarios, un volumen de cuentos y siete novelas. Mis poemas casi no los conoce nadie, lo que probablemente esté bien. Mis libros de prosa tienen algunos lectores fieles, lo que probablemente sea inmerecido." (BOLAÑO, 2014: 19).

${ }^{4}$ Para las diversas facetas de la relación entre Nicanor Parra y Roberto Bolaño, descritas por él mismo, cf. BOLAÑO, 2014: 92 ss., 133 ss. 
de Nicanor Parra, quien paradójicamente supo despojarse, después de una larga lucha por la diferenciación, de cualquier tipo de esteticismo metafísico.

En vista de que el espacio sólo permite una breve comparación, quisiéramos elucidar a través de dos antologías líricas que aparecieron con apenas medio siglo de diferencia, que el ímpetu existencial de las novelas a pesar de las convencionalidades lexicales, sólo puede comprenderse a través de los intentos de liberación de la reflexión del lenguaje lírico en su dimensión profunda y radical entre la posibilidad de convencionalización y la reflexión del sujeto.

El novelista Bolaño es incomprensible sin el poeta Bolaño, de la misma forma como no se puede comprender el éxito de la literatura latinoamericana como intérprete de la actualidad si no se toma en consideración su raigambre en la poesía del Modernismo, de la Vanguardia y sus desesperados intentos por superarlos. Si hace sesenta años, los Poemas y antipoemas (1954) de Parra conformaban por un lado la suma negada de los Modernistas, Vanguardistas, de la lírica de Pablo Neruda y finalmente la propia desesperación ante la novedad del "Anti-poème" que, refiriéndose a Henri Pichette, al principio llamó "A-poème" (PARRA, 1988: 19), Bolaño, después de varios preejercicios en los ańos setenta, ${ }^{5}$ logra llamar la atención como poeta lírico en primer lugar con sus Perros románticos (1993) y va de nuevo en busca de los límites de la lengua en su conformación lírica a finales del siglo XX, en su último volumen de poemas titulado Tres (2000).

Probablemente gracias - entre otros - a Nicanor Parra, Bolaño logra ganar confianza en el poder de las vanguardias a partir de la oposición al pensamiento de coherencias neorromántico, sin caer en un experimento frio de esoterismo lírico a raíz de su provocador cálculo:

Un apunte político: Parra ha conseguido sobrevivir. No es gran cosa, pero algo es. No han podido con él ni la izquierda chilena de convicciones profundamente derechistas ni la derecha chilena neonazi y ahora desmemoriada [...] Ni siquiera los seguidores de Parra han podido con Parra. Es más, yo diría, llevado seguramente por el entusiasmo, que no sólo Parra, sino también sus hermanos, con Violeta a la cabeza, y sus rabelesianos padres, han llevado a la práctica una de las máximas ambiciones de la poesía de todos los tiempos: joderle la paciencia al público. [...] La poesía de las primeras décadas del siglo XXI será una poesía híbrida, como ya lo está siendo la narrativa. Posiblemente nos encaminamos, con una lentitud espantosa, hacia nuevos temblores formales. En ese futuro incierto nuestros hijos contemplarán el encuentro sobre una mesa de operaciones del poeta que duerme en una silla con el pájaro negro del desierto, aquel que se alimenta de los parásitos de los camellos. (BOLAÑO, 2004b: 93)

Sin embargo, contrario a los programas de vanguardia y con menos confianza en su ira histórica que Bolaño, Nicanor Parra era consciente de que una

\footnotetext{
${ }^{5}$ Gorriones cogiendo altura (1975, no publicado) y Reinentar el amor (1976).
} 
ruptura con la forma lírica sólo era posible en la medida de una afirmación de la forma sistémica de la lengua como una necesidad de continuidad histórica. La búsqueda estructuralista de una función poética de la lengua, tal y como salía a relucir más tarde en el análisis sobre Baudelaire ejecutado por Claude Lévi-Strauss y Roman Jacobson en "Les Chats' de Charles Baudelaire" (cf. JAKOBSON, 1962) no había salido de la discusión no solamente acerca del empleo histórico de la lengua y su renovación, sino de un cuestionamiento general de su funcionalización comunicativa. ${ }^{6}$

Las tres partes de su volumen de poemas aparecido en 1954 dan fe de una estrategia de la emancipación funcional e histórica de patrones comunes de la lengua, sin perder la comunicación con el lector, ya que Parra se sirve de todo tipo de registros de la lengua (jerga, caló etc.) para mantener el vínculo con sus lectores. Como Ludwig Wittgenstein, confía en la trascendencia de la lógica del sistema lingüístico, el cual para el filósofo construye hechos que, aunque no se pueda cualificarles como 'reales', están ónticamente en el mismo plano como hechos estéticos y éticos. Confía, por eso, en la posibilidad de dar sentido al mundo por lo pensable y en contra de lo 'real'. 7 Parra considera el Tractatus como un desafío a la estética kantiana que todavía impregna la poesía contemporánea:

Los mortales que hayan leído el Tractatus de Wittgenstein / Pueden darse con una piedra en el pecho / Porque es una obra difícil de conseguir: / Pero el Círculo de Viena se disolvió hace años, / Sus miembros se dispersaron sin dejar huella / y yo he decidido declarar la guerra a los cavalieri della luna. (PARRA, 1988: 81)

Las palabras de Parra establecen un juego con los contrastes, con tópicos y estereotipos intelectuales y históricos del uso poético de la lengua, que le llevan a encontrar aquel camino, que hace que la 'antipoesía' se convierta más bien en una síntesis, que en una negación de sujeciones histórico-líricas del espíritu de la lengua en la convención. Una vez más Parra sigue a Wittgenstein y 'descarta la escalera' de la lengua después de que él la había colocado. La primera parte de sus Poemas y antipoemas, que se ocupa de los antecedentes modernistas, se convierte por ello para el lector en una impla-

\footnotetext{
${ }^{6}$ Para Parra interpretado por Jakobson, cf. CUADRA, 1997: 19; YAMAL, 1985: 33 ss.

${ }^{7} 6.421$ "Está claro que la ética no resulta expresable. La ética es trascendental. (Etica y estética son una y la misma cosa.) / 6.422 Cuando se asienta una ley ética de la forma "tú debes..." el primer pensamiento es: ¿y qué, si no lo hago? Pero está claro que la ética nada tiene que ver con el premio y el castigo en sentido ordinario. Esta pregunta por las consecuencias de una acción tiene que ser, pues, irrelevante. Al menos, estas consecuencias no deben ser acontecimientos. Porque algo correcto tiene que haber, a pesar de todo, en aquella interpelación. Tiene que haber en efecto, un tipo de premio y de castigo éticos, pero éstas han de residir en la acción misma (y está claro, asimismo, que el premio ha de ser algo agradable y el castigo algo
}

desagradable) (WITTGENSTEIN, 1989: 177). 
cable develación de las decepcionantes expectativas propias ante aquello que debería ser 'lírico'.

La crítica de Parra a la admirada Gabriela Mistral, por ejemplo, se evidencia en un principio también en una parodia, pero en primer lugar es una reversión de las fórmulas de conjuro finiseculares a la vida en el enclaustramiento de la forma como una adaptación por momentos cauta, por momentos salvaje de la forma a la vida. Si contrastamos el poema de Parra, Sinfonía de cuna sobre el feroz encuentro con un ángel, con El Ángel guardián (1924) de Gabriela Mistral (aquí 2014), ${ }^{8}$ es evidente que el escape hacia el reino del arte se bloquea una vez más intencional y afirmativamente, sin por ello negar, a través del empeño innovador vanguardista, las esperanzas de los Modernistas y su sensibilidad por todo lo que se refiere a la lengua:

Una vez andando / Por un parque inglés / Con un angelorum / Sin querer me hallé // Buenos días, dijo, / Yo le contesté / Él en castellano, / Pero yo en francés. // Dites moi, don angel, / Comment va monsieur // Él me dio la mano, / Yo le tomé el pie: / Hay que ver, señores, / Como un ángel es! // Fatuo como el cisne, / Frío como un riel, / Gordo como un pavo, / Feo como usted. // Susto me dio un poco / Pero no arranqué. [...] (PARRA, 1988: 51)

Parra parodia, pero también sabe escuchar. Esto lo notamos, cuando en la segunda parte nos encontramos con otro tipo de intención, la vuelta al pueblo sin rodeos y sin enredos, la que a su vez se somete a una inversión irónica. Al colega "montruoso" de Parra, Pablo Neruda, se le respeta en la medida en que se retoma el gesto lingüístico de los culteranismos adaptados por Neruda no solamente en sus Odas elementales (1954), aunque ahora es el gesto del propio poeta el que es relativizado en su importancia en aras de una fuerza emancipadora de cualquier tipo de poesía. Esto sucede, cuando al "Yo me río, me sonrío" del "Hombre invisible" de Neruda (2005: 9) se le contrapone un "Autorretrato" resignado de Parra (1988: 73). Ni siquiera la belleza en su calidad de ideal absoluto en el sentido ontológico es ya asunto del poeta, en tanto ella tiene que seguir siendo un producto relativo de la contingencia situacional. Al yo lírico se le otorga el rol del testigo, nunca el del interpretador.

Si se compara la famosa reversión de la técnica nerudiana por parte de Parra en la "Oda a unas palomas" con la técnica de la oda aplicada por Neruda, se nota la fuerza de un elogio transformador de lo cotidiano que ha cedido su lugar a una certeza banal pero existencial del carácter prioritario

\footnotetext{
8 "Es verdad, no es un cuento; / hay un Ángel Guardián / que te toma y te lleva como el viento / y con los nińos va por donde van. // Tiene cabellos suaves / que van en la venteada, / ojos dulces y graves / que te sosiegan con una mirada / y matan miedos dando claridad. / (No es un cuento, es verdad.) // Él tiene cuerpo, manos y pies de alas / y las seis alas vuelan o resbalan, / las seis te llevan de su aire batido / y lo mismo te llevan de dormido [...]" (MISTRAL, 2014).
} 
de lo cotidiano (cf. PARRA, 1988: 29-32). De ahí resulta también la necesidad de una transformación del lenguaje poético que se convierte en lenguaje de la vida. El lector ya no siente sobrecogimiento, pero le queda una sonrisa irónica acerca de indignación que siente en la primera parte, cuando se da cuenta de que la realidad ha sido desarropada con ayuda de la forma modernista. No obstante, esta reversión también es parte de una reflexión que no abarca únicamente dimensiones históricas. La última parte de su volumen de poemas es un implacable altercado con las propias exigencias en relación a la poesía. Lo que queda es el ser humano, que ya no puede ser salvado a través de la lengua, pero que se siente obligado frente a ella, tal y como se nota en los últimos versos del "Soliloquio del individuo", donde concluye el ciclo poético con el conjuro fragmentado y alabador a la propia soledad del 'yo' indivisible; pareciéndose pero diferenciándose también del himno final de Francesco Petrarca a la "Vergine bella, che di sol vestita, coronata di stelle" en su Rerum vulgarium fragmenta, donde, a principios de la era moderna, el 'yo' debe ceder el paso al nombre de la Virgen, a la trascendencia. ${ }^{9}$ Parra y el individuo (pos-)moderno no quieren ceder:

Yo soy el Individuo. / Miré por una cerradura, / Sí, miré, qué digo, miré, / Para salir de la duda miré, / Detrás de unas cortinas, / Yo soy el Individuo. / Bien. / Mejor es tal vez que vuelva a ese valle, / A ese roca que me sirvió de hogar, / Y empiece a grabar de nuevo, / De atrás para adelante grabar / El mundo al revés. / Pero no: la vida no tiene sentido. (PARRA, 1988: 116)

Parra tiene que expresarse para poder aguantar y desarrolla con este gesto performativo un nuevo ritmo de lo poético, que encuentra su razón de ser en el hecho de retomar, transformándola, la forma, no la vida. El término de lo absurdo, tal y como lo acuñara Albert Camus, en aquellos años ya es lugar intelectual común; ${ }^{10}$ no obstante, Parra lo lleva hasta sus límites, en tanto retoma el juego formal de la lengua, rebelándose contra las esperanzas vanguardistas, con toda la modestia ante las deficiencias humanas, y lo juega según sus reglas, que ya no son las reglas hacia una meta revolucionaria en el sentido que le dieran las vanguardias. No se puede encontrar aquí ni una emancipación del aparato del yo psicoanalíticamente diferenciado, tal y como se pudiera esperar de los surrealistas, ni una glorificación de un enfoque vitalista en la técnica y capacidad de producción del ser humano. Parra probablemente está más lejos de los futuristas cuando coloca su propia fra-

\footnotetext{
9 "Il dí s'appressa, et non potè esser lunge, / sí corre il tempo e vola, / Vergine unica e sola, / e’l cor or coscientia or morte punge. / Raccomandami al tuo figliuol, verace / homo e verace Dio, / ch'accolga il mïo spirto ultimo in pace" (PETRARCA, 1964: 447).

${ }^{10}$ El mito de Sisifo apareció en 1942, El hombre rebelde en 1951; un paralelismo entre Parra y Camus indican Campaña (1995: 35) y Salinas (2014: 35).
} 
gilidad como el escándalo en sí en el centro de su poesía. Pero, ¿cómo lo ve su admirador Bolaño?

En su también muy delgado volumen de poemas Tres parece tener las mismas exigencias radicales hacia la forma, que al parecer no habían podido resolver los vanguardistas. Bolaño retoma la división en tres partes de Parra, sin situarla empero en un contexto histórico o mejor dicho, en una teleología de la reflexión del 'yo'. Más bien encontramos en él un movimiento de búsqueda que prescinde de la tan añorada epifanía de lo lírico. En lugar de ello pregunta acerca de lo que lo lírico significa en sí para la lengua. Partiendo de la situacionalidad lírica, que se convierte en forma de apuntes prosísticos, cuando en la primera parte le siguen a bloques textuales poéticamente densos medias páginas en blanco ("Prosa del otoño a Gerona”, cf. BOLAÑO, 2011: 4 ss.), continua hacia lo diegético en el contenido de versos lírico en forma de una 'narración de viaje' ("Los neochilenos", cf. BOLAÑO, 2011: 76 ss.) sin aliento en la segunda parte, que convierte esta forma de estrofas en pura mácula a causa del los fragmentos experimentados, narrados y acumulados con tanta prisa. La tercera parte del tomito conforma una reflexión sobre la literatura como un espacio en blanco epistemológico: una 'lista poética' representa el punto final del viaje ("Un paseo por la literatura”, cf. BOLAÑO, 2011: 114 ss.).

Para la dimensión de la lengua esto significa que su formalización, como división lírica en estrofas y versos, no le confiere al 'yo' lírico el apoyo de un orden mediato y comunicativo. La división tripartita realizada por Bolaño obedece así también a una centralización en una prosa poética que ha sido despojada de sus ataduras convencionales, que en última instancia tiene que ser la forma del 'yo' lírico, para no contar más de lo que se quiere narrar, sino colocar en primer plano la vida y la vivencia como problemas del individuo en una disposición temporal de diégesis épica. Al mismo tiempo nos da a entender mediante esta estructuración, de qué forma se puede revivir la función lírica de una autenticidad aprehendida formalmente, desde hace mucho tiempo perdida, mediante un compromiso con las lógicas del narrar.

El vínculo entre literatura y enfermedad es otro aspecto que une ambos poetas. ${ }^{11}$ Sin embargo, en Parra los males sólo afectan al 'yo' lírico, con su "lengua roída por el cáncer" (PARRA, 1988: 73); en cambio, Bolaño critica la enfermedad de la lengua engastada en el sistema, que no puede y tampoco

\footnotetext{
${ }^{11}$ En relación con Parra y la metáfora de la "enfermedad" en sus obras y como imágen aplicada a la literatura (chilena y general) compárese RODRÍGUEZ FERNÁNDEZ, 1996: 30; GOTTLIEB, 1977: 85. En cuanto al vínculo entre enfermedad y literatura en Bolano ver su ensayo "Leteratura + Enfermedad = Enfermedad”, publicado en El gaucho insufrible (2003, aquí 2010: 515-533). Para el tema de la enfermedad en la lírca de Bolańo cf. los ensayos de María Eugenia Fernández $(2010,2013)$
} 
debe abrirle paso a lo novedoso, porque ella misma, aunque menos en la lírica, trata de domar lo nuevo. La novedad, que podrá existir como lo radical, lo inaudito, lo malo, lo que nunca ha sido, solamente será cuando abandone la lengua en un espacio de lo real, que asimismo se convierte en lo inquietante o incluso terrible, si se le quisiera domar a tientas a través de la lengua. La enfermedad en la lengua se convierte aquí en la enfermedad del sobrante sin trabajar de la experiencia real. Expresándose en términos nietzscheanos, Bolaño habla aquí de lo 'dionisiaco':

Dionisio lo ha invadido todo. Está instalado en las iglesias y en las ONG, en el gobierno y en las casas reales, en las oficinas y en los barrios de chabolas. La culpa de todo la tiene Dionisio. El vencedor es Dionisio. Y su antagonista o contrapartida ni siquiera es Apolo, sino don Pijo o dońa Siútica o don Cursi o doña Neurona Solitaria, guardaespaldas dispuestos a pasarse al enemigo a la primera detonación sospechosa. (BOLAÑO, 2010: 521)

A diferencia de Parra, que con su anti-poesía eligiera el camino del parodiador acaparamiento e impedimento, Bolaño decide seguir el camino de Mallarmé y Baudelaire. ${ }^{12} \mathrm{Si}$ en la segunda parte de los "Neochilenos" una sucesión de palabras agolpada, arrojada en forma de estrofas por una voz narradora, cae como avalancha sobre el lector y también se llevará por delante aquel espacio de la página del libro que vagamente recuerda América Latina, pero que, como el "Coup de dés" de Mallarmé, abre el espacio narrado del viaje hacia lo metafísico de lo contingente tanto exterior como interior:

En un Chile inexistente / Y feliz. / Y aquella historia tuvo la virtud de iluminar / Como un paisajista inglés / Nuestro miedo y nuestros sueños / Que marchaban de Este a Oeste / Y de Oeste a Este, / Mientras nosotros, los Neochilenos / Reales / Viajábamos de Sur a Norte. (BOLAÑO, 2011: 106-107)

No obstante, el lanzamiento al viaje 'real' y 'soñado' comienza muy poco espectacular: El viaje comenzó un feliz día de noviembre / Pero de alguna manera el viaje ya había terminado / Cuando lo empezamos (BOLAÑO, 2011: 78).

Para las/los viajeros "neochilenos", el espacio temporal de la trayectoria del camino sin rumbo se convierte en el "purgatorio" en los países latinoamericanos, un diluvio de trozos históricos y asociativos entre poetas, patrullas militares y clubes nocturnos: $Y$ recordé entonces que el día / Anterior a nuestra partida / Habíamos estado / En el Parque Forestal / De visita en el monumento / A Rubén Darío. / Adiós, Rubén, dijimos borrachos / Y drogados (BOLAÑO, 2011: 80).

\footnotetext{
${ }^{12}$ Según Markus Messling, Bolaño representa una "antropología pesimista del capitalismo" baséndose principalmente en el trabajo preliminar de Baudelaire (cf. MESSLING, 2014: 202-208).
} 
Si el 'antipoeta' Parra al final encuentra la lengua monológica del individuo, Bolaño, a pesar de un final previsible con las herramientas disponibles de la lengua y con ayuda de la lengua formal lírica, da su consentimiento para la narración de lo imposible con el apoyo de las convenciones colectivas del uso de la lengua, sin aceptar empero su valor epistemológico. La única salida de la enfermedad de la lengua, que ya habían descubierto los poetas de las postrimerías del siglo XIX, muestra el camino de vuelta a una narración, la enumeración prosaica de lo limitante como "paseo por la literatura". El viaje se convierte en un arraigo a la función narrativa y organizadora de la lengua incluso durante el sueño: "Soñé" se convierte en un término clave en una lista de imposibilidades (cf. BOLAÑO, 2011: 122 ss.). ${ }^{13}$

Este proceso asimismo se refleja en las obras de Bolaño en la descripción de lo posible por medio de caricaturas, sombras y fantasmas de poetas, tal y como obedecen a la ficcionalización de lo ficcionable en Borges y acompañan la obra hundida en calidad de quimeras. La misma obra carece en última instancia de cualquier interés, en cuanto la búsqueda en sí de los arqueólogos y científicos de la literatura sólo se enfoca hacia aquella realidad vivida que se refleja y vuelve a reflejar. Sin embargo, también se refleja en aquella parte central "de los crímines" en 2666 (cf. BOLAÑO, 2004a: 441 ss.), en el momento en que es sólo la lista de los cuerpos lacerados la que mantiene los vínculos con el mundo. En las obras de Bolaño, la búsqueda de trazos de la vida en la enfermedad se convierte, a pesar de la cruel enfermedad de un placer freudiano por la muerte, en un intenso trabajo detectivesco. No obstante, este trabajo puede comenzar apenas allí, donde es evidente, que es la función poética de la palabra en sí, tal y como se puede percibir por medio de las vueltas formales en métrica, y esquemas de rima y estrofa de la lírica, la que en principio ha llevado hacia la enfermedad a causa de su supuesta soberanía sobre la vida: ¿Y dónde diablos está el maricón de Apolo? Apolo está enfermo, grave (BOLAÑO, 2010: 521).

Sólo por esta desconfianza frente al poder de la forma en la literatura se logra comprender, por qué la última parte de Tres, bajo el título "Un paseo por la literatura" se convierte en un recuento poético allende toda lógica. Poesía y prosa llegan a un compromiso poco satisfactorio por una racionalidad de lo irracional, tal y como lo subrayara María Eugenia Fernández refiriéndose al Orden de las cosas de Michel Foucault. ${ }^{14} \mathrm{Y}$ en esta desconfianza

\footnotetext{
${ }^{13}$ En este sentido quiero seguir Michael Dowdy (2013: 96-106), que hace hincapié en la continuidad de la función crítica de la respectiva concepción de escritura en Parra y Bolano, pero recalco nuevamente sus diferentes maneras de utilizar la lírica.

14 "Bolaño, en un gesto de filiación con Borges, muestra otra vez que no existe una relacíon unívoca entre 'palabra' y 'cosa' [...] Pero en la modernidad, el lenguaje no ya no es un lugar seguro, un
} 
Bolaño y Parra difieren fundamentalmente en cuanto a sus respectivos conceptos de lo lírico.

Únicamente sobre la base de esta forma pesimista de comprender la lengua se puede entender, porqué el 'informe' "Los neochilenos", con su forma estrófica pretendida y su lengua de crónica personal, se encuentra en el centro de las dos alas del 'Tríptico' literario que en su forma prosística juegan con la lógica imposible de la lengua lírica, y fungen como la estructura dominante de Tres. La lengua misma como lengua de la poesía lírica pierde su función como densificadora, porque más bien disuelve la estructura de coherencia que conecta las palabras con el mundo de la experiencia. Sin embargo, es el juego con lo metafórico, el que en la primera parte "Prosa del otońo en Gerona" permite una mirada, si no ya a lo novedoso de una realidad de lo desconocido, por lo menos a distinguir la nostalgia por lo extraño. Esta parte corresponde a la crítica de Parra contra el Modernismo en su primera parte de "Poemas y antipoemas", en tanto son de nuevo los fragmentos de las convenciones líricas las que se encuentran a debate y se desechan a la luz de su valor de identificación general como fútil para la comunicación del sentido subjetivo. Roberto Bolaño en este sentido es más radical pero también más modesto que Parra, porque la vivencia de la lengua de aquello que la apreciación colectiva describe como 'historia de la literatura' y la convención lírica pone a la disposición como material de expresión, se encuentra por encima de las vivencias propias del sujeto ridículo que se desespera haciendo poesía. $\mathrm{Al}$ mismo tiempo esta vivencia solamente puede ser demandada por la 'generalidad' en forma de una narración. Bolaño justifica así la lírica como el núcleo verdadero, por auténtico, de su vivencia, para deshacerse de él con tristeza en favor de su producción en prosa. Esto se pone de relieve en el siguiente fragmento de la primera parte que asimismo es una crítica aguda al rol del 'yo' creando poesía transformadora en el "Hombre invisible" de Neruda. El "instante Atlántida” se queda fuera del espejo del poeta en su reflexión:

Para acercarse a la desconocida es necesario dejar / de ser el hombre invisible. Ella dice, con todos sus / actos, que el único misterio es la confidencia futura. / ¿La boca del hombre se acerca al espejo? / Sácame de este texto, querré decirle, muéstrame / las cosas claras y sencillas, los gritos claros y senci- / llos, el miedo, la muerte, su instante Atlántida ce- / nando en familla. (BOLAÑO, 2011:31-32).

Si el volumen de poemas de Parra termina con la confesión "la vida no tiene sentido" (PARRA, 1988: 116), aunque aún tiene suficiente confianza en la lírica para dejarla actuar como punto neurálgico de la expresión de la lengua,

piso firme, sino un espacio en ruinas que inquieta, es como un suelo escarpado al borde del cual hay un abismo insondable." Cf. FERNÁNDEZ, 2010: 30. 
Bolaño concluye parcamente: "No tiene sentido escribir poesía" (BOLAÑO, 2011: 34). Ambos caminos llevaron al éxito y perfilan concepciones de la poesía actual y de actualidad, que pueden mostrar posibles salidas al dilema de la fragilidad postestructuralista en cuanto a las relaciones referenciales de las lenguas. En el mejor de los casos no le conferiría solamente al género de la novela una confianza cada vez menor en la comprehensión a partir de evocaciones aparentemente coherentes acerca de una complejidad de lo global que ya no se podría representar por medio de las estrategias literarias presentes, que únicamente logran crear la ilusión del sentido en lo universal de una antropología existencial.

En sus poemas, dos autores latinoamericanos han reconsiderado un problema, que hizo fracasar el proyecto de las vanguardias europeas. Con los recursos a la poesía dasafiaron la falta de sentido metafísico sin destruir la lengua. Parra satirizó toda la tradición - (no sólo) la poesía latinoamericana. Él parodió y llevó a cabo su lucha contra la poesía con sus reivindicaciónes de una estética idealista. Así que él no apostó sólo a la antítesis histórica como los surrealistas y futuristas, sino también al sentido de la síntesis en una continuidad de la búsqueda histórica de la literatura como creadora de muchos sentidos. Bolaño dejó de sobra la lírica como comunicativa desesperada de la experiencia individual, aunque válida, y se dedicó a la Prosanarration, o más bien a una estructura circular de la lista como una forma prescrita y adecuada a la experiencia colectiva en tiempos del materialismo ontológico, que se traduce en sus novelas: A pesar de sus restricciones epistemológicas, la prosa parece el medio privilegiado de la comunicación humana de nuestra época, pero Bolaño demostró además que sólo el juego de la poesía puede hacer visible las restricciones y el espacio antropológico y ético de la palabra. Por eso, Nicanor Parra y también Bolańo eran conscientes en última instancia que la pérdida de sentido metafísico y de la palabra iban a repercutir en el rol social y político de la literatura. Parra veía que la crítica poética, versada en las formas líricas, no contenía ninguna función epistemológica allende la propaganda que provenía de la situación histórica de Chile. Por eso su crítica a Neruda. Bolaño prescinde desde el inicio de esta crítica directa a las pretensiones epistemológicas y le cede a la lírica la labor de seguir las declaraciones filosóficas de Foucalt, de que epistemología siempre debe ser histórica. Ambos autores sabían sin embargo que, más allá de esta epistemología, era únicamente la función poética de la propia lengua la que antecedía cualquier lírica y se densificaba en ella. A pesar de todos los intentos fallidos por lo menos pudieron crear esa parte negativa en la distancia hacia las lógicas de las relaciones de referencia, que por un instante hacía posible la comunicación interpersonal en tanto se compartía la vivencia lejos de lo meramente mimético: 50. Soñé 
que después de la tormenta un escritor / ruso y sus amigos franceses optaban por la / felicidad. Sin preguntar ni pedir nada. Como quien / se derrumba sin sentido sobre su alfombra favorita (BOLAÑO, 2011: 166).

Parra asimismo no duda de que lo poético también está presente en lo indeterminado y ambivalente:

Sin embargo, el mundo ha sido siempre así. / La verdad, como la belleza, no se crea ni se pierde / Y la poesía reside en las cosas o es simplemente un / [espejismo del espíritu... Tratemos de ser felices, recomiendo yo, chupando / [la miserable costilla humana. / Extraigamos de ella el líquido renovador, / Cada cual de acuerdo con sus inclinaciones personales. (PARRA, 1988: 109)

El juego con la función poética de la palabra como intento de emancipación serían un elemento existencial positivo tanto para Parra como para Neruda y en este sentido no como la literatura, entendida como un sistema epistemológico de la aceptación convencionalizada de la enfermedad, sino como prueba de que en cada momento el uso consciente de la lengua nos puede liberar de la coerción de una interpretación tiránica del ser humano por la política, la economía o los estudios culturales por un lado y por el otro, por la filosofía, del arte normado o la literatura. Sin haberle impuesto a lo actual una estética y una lógica nuevas, tanto Parra como Bolaño fueron dos poetas que pusieron en duda la lírica, que le deben muchos de sus impulsos a la prioridad que los Modernistas y los vanguardistas le dieron a la lengua y la salvaron en última instancia para el presente: la aceptación de que era, es y será posible alcanzar la libertad existencial-filosófica por medio de la lengua. Sin embargo, lo es sólo bajo la condición de que la conciencia acerca de la limitación, consecuencia del centro de la metafísica vacío, no se rellene con la esperanza de una trascendencia formal de la lengua o el fantasma tan presente de su univocidad. La única certeza trascendental que queda es la siempre renovada apertura de este proceso formal en un juego repetido con el léxico y con la gramática, pero también la posibilidad siempre presente de transmitir horizontes de comprehensión y propuestas al lector, esto es, lo que se entiende por literatura. No obstante, esta certeza de ninguna manera es un juego desolador y frio con los signos, sino que son los signos mismos, los que en su deficiencia y banalidad hacen reconocer, si no un sujeto, por lo menos una intencionalidad comunicativa, que los pone en movimiento. ${ }^{15} \mathrm{La}$ meta de cualquier esfuerzo antropológico del animal reflexivo, el humano, sería la

\footnotetext{
${ }^{15}$ Ottmar Ette (2008: 173) ha puesto de relieve la importancia de las formas literarias cortas como formas de comunicación contemporánea, citando también la falta de especialización de la filología en estos importantes productos literarios. Cf. también ETTE, 2009 y ETTE et al., 2015, una antología que proporciona importantes enfoques teóricos e históricos en géneros nuevos que se establecen entre otros en el campo de las redes sociales.
} 
creación de un sistema de metasignos, que contuviese todos los demás sistemas de signos, cuya función fuera relacionarlos y hacerlos comprensibles. Borges había ya pensado en esto, pero su objetivo era más bien un juego de probabilidades con los signos en sí y menos un desplazamiento cualitativo dentro de los límites de cada uno de los géneros. En la poesía lírica se logra aquella distancia que hace que se pueda por lo menos prever, a pesar de toda la ambivalencia, este ideal intersubjetivo de una comunicación auténtica y multifacética, por encontrarse allende la pregunta por su convencionalización, donde la sistemática de una epistemología normada le impide la visión a la prosa y a las novelas. Por eso sería oportuno considerar Latinoamérica como un continente de la lírica y no únicamente como el del boom de la novela, para apoyar la lírica en su tarea de unificación intersubjetiva y no convertir la supuesta crisis de la textualidad en una crisis de las formas literarias.

\section{Referencias bibliográficas}

BATAILLE, Georges. La Littérature et le Mal. Paris: Gallimard, 1957: 35-68.

BLUMENBERG, Hans. Die Lesbarkeit der Welt. Frankfurt: Suhrkamp, 1986.

BOLAÑO, Roberto. 2666. Barcelona: Editorial Anagrama, 2004a.

. Entre paréntesis: ensayos, artículos y discursos (1998-2003). Barcelona: Anagrama, 2004b.

. Cuentos. Barcelona: Anagrama, 2010.

. Tres. Bilingual Edition. Trad. Laura Healy. New York: New Directions, 2011.

BOLOGNESE, Chiara. Pistas de un naufragio: cartografía de Roberto Bolaño. Santiago de Chile: Editorial Margen, 2009.

CAMPAÑA, Antonio. Poesía y situación de Nicanor Parra: los comentarios. Santiago: Ediciones del Instituto de Estudios Poéticos, 1995.

CASANOVA, Pascale. La République mondiale des Lettres. Éd. revue et corigée. Paris: Seuil, 2008.

CUADRA, César. Nicanor Parra: en serio \& en broma. Santiago: Ed. del Departamento de Estudios Humanísticos, Univ. de Chile, 1997.

DAMROSCH, David. What is World Literature? Princeton: Princeton UP, 2003.

DOWDY, Michael. Broken Souths: Latina/o Poetic Responses to Neoliberalism and Globalization. Tucson: The University of Arizona Press, 2013.

ESPINOSA, Patricia (Ed.). Territorios en fuga: estudios críticos sobre la obra de Roberto Bolaño. Santiago: Frasis, 2003.

ETTE, Ottmar. "Sendas del saber: cinco tesis acerca de la conciencia universal y las literaturas del Caribe y del mundo", Ibero-Americana Pragensia, n. 18, 2006: 249-264.

. "Epistemologie der écriture courte - écriture courte der Epistemologie. Versuch einer Antwort auf die Frage, Was ist Nanophilologie". In: 
(Ed.). Nanophilologie: Literarische Kurz- und Kürzestformen in der Romania. Tübingen: Niemayer, 2008: 167-186.

. Del macrocosmos al microrrelato: literatura y creación - nuevas perspectivas transareales. Trad. Rosa María S. de Maihold. Guatemala: F \& G Editores, 2009.

ETTE, Ottmar; INGENSCHAY, Dieter; SCHMIDT-WELLE, Friedhelm \& VALLS, Fernando (Ed.). MicroBerlin: de minificciones y microrrelatos. Frankfurt; Madrid: Vervuert; Iberoamericana, 2015.

FERNÁNDEZ, María Eugenia. "Literatura y abismo: una poética de lo nuevo en Tres de Roberto Bolaño”. Cifra Nueva, n. 22, 2015: 19-32.

"Aproximaciones a la poética de Tres, de Roberto Bolaño", Nueva Revista de Filología Hispánica, v. 61, n. 1, 2013: 203-218.

GOTTLIEB, Marlene. No se termina nunca a leer: la poesía de Nicanor Parra. Madrid: Colección Nova Scholar, 1977.

JAKOBSON, Roman \& LEVI-STRAUSS, Claude. “Les Chats” de Charles Baudelaire”, L'Homme, n. 2, 1962: 5-21.

LÓPEZ DE ABIADA, José Manuel (Ed.). Roberto Bolaño, estrella cercana: ensayos sobre su obra. Madrid: Verbum Editorial, 2012.

LOY, Benjamin. "Escritores bárbaros, detectives distantes y un cura amnésico: escenificaciones de la memoria (post-)dictatorial chilena en la obra de Roberto Bolaño”. In: PAATZ, Annette \& REINSTÄDLER, Janett (Ed.). Arpillera sobre Chile: cine, teatro y literatura antes y después de 1973. Berlin: Edition Tranvía, 2013: 117-138.

MANZONI, Celina (Ed.). Roberto Bolaño: la escritura como tauromaquia. Buenos Aires: Corregidor, 2002.

MESSLING, Markus. “2666: Die Moderne als Echolot der Globalisierung. Roberto Bolaño und das Erbe Baudelaires”. In: ETTE, Ottmar \& WIRTH, Uwe (Ed.). Nach der Hybridität: Zukünfte der Kulturtheorie. Berlin: Edition Tranvía, 2014: 199-215.

MISTRAL, Gabriela. "El Ángel Guardián”, Ternura, Santiago: Editorial Universitaria, 2014: 198-199.

MORETTI, Franco. "Conjectures on World Literature”, New Left Review, n. 1, 2000: 54-68.

NERUDA, Pablo. Odas elementales. Santiago: Pehuén Editores, 2005.

PARRA, Nicanor. Poemas y antipoemas. Ed. René de Costa. Madrid: Cátedra, 1988.

PETRARCA, Francesco. Il Canzoniere. A cura di Giancarlo Contini. Torino: Einaudi, 1964.

POLANCO SALINAS, Jorge. "La política de los artecfactos: 8 Retazos a propósito del centenario de Nicanor Parra”. TRASATLANTICA 3, año 2, 2014: 28-35.

RÍOS BAEZA, Felípe (Ed.). Roberto Bolaño: ruptura y violencia en la literatura finisecular. México D. F.: Ediciones Eón, 2010.

RODRÍGUEZ, Franklin. Roberto Bolaño: el investigador desvelado. Madrid: Editorial Verbum, 2015.

RODRÍGUEZ FERnÁNDEZ, Mario. Orbita de Nicanor Parra. Concepción: Universidad de Concepción, 1996. 
SOLOTOREVSKA, Myrna. El espesor escritural en novelas de Roberto Bolaño. Rockville: Ediciones Hispamerica, 2012.

VALDIVIA OROZCO, Pablo. Weltenvielfalt: Eine romantheoretische Studie im Ausgang von Gabriel García Márquez, Sandra Cisneros und Roberto Bolaño. Berlin: De Gruyter Mouton (Mimesis 56), 2013.

WITTGENSTEIN, Ludwig. Tractatus Logico-Philosophicus: texto en alemán y en castellano. Trad. e intro. J. Muñoz e I. Reguera. Madrid: Alianza, 1989.

YAMAL, Ricardo. Sistema y visión de la poesía de Nicanor Parra. Valencia: Albatros, 1985.

Markus Lenz é pesquisador do Departamento de Literaturas Românicas da Universidade de Potsdam. Doutorou-se com uma tese sobre as narrativas raciais e etnocêntricas que afetam a historia da filologia italiana no século XIX, publicada em 2014 sob o titulo Genie und Blut. Rassedenken in der italienischen Philologie des 19. Jahrhunderts (Editora Wilhelm Fink, Munique, Paderborn).

E-mail: marlenz@uni-potsdam.de 